\title{
Effect of matrine on JAK2/STAT3 signaling pathway and brain protection in rats with cerebral ischemia-reperfusion
}

\author{
Jixing Chen ${ }^{1, A-D}$, Cuiqin Huang ${ }^{2, B, C}$, Lichao Ye ${ }^{1, D}$, Boxin Ya0 $0^{1, E}$, Meili Yang ${ }^{1, E}$, Qiankun Cai ${ }^{1, E}$ \\ ${ }^{1}$ Department of Neurology, The Second Affiliated Hospital of Fujian Medical University, Quanzhou, China \\ ${ }^{2}$ Department of Neurology, Quanzhou Hospital of Traditional Chinese Medicine, China \\ A - research concept and design; $B$ - collection and/or assembly of data; $C$ - data analysis and interpretation; \\ $D$ - writing the article; $E$ - critical revision of the article; $F$ - final approval of the article
}

\section{Address for correspondence \\ Jixing Chen \\ E-mail: chenjixing08djf@163.com}

\section{Funding sources}

This work was supported by the Project of the Science and Technology Bureau of Quanzhou for Effect of early tirofiban administration on cerebral blood perfusion and endothelial function in Acute Ischemic Stroke patients treated with mechanical thrombectomy (grant No. 2017Z003)

\section{Conflict of interest}

None declared

Received on December 1, 2019

Reviewed on April 14, 2020

Accepted on June 2, 2020

Published online on August 21, 2020

Cite as

Chen J, Huang C, Ye L, Yao B, Yang M, Cai Q. Effect of matrine on JAK2/STAT3 signaling pathway and brain protection in rats with cerebral ischemia-reperfusion. Adv Clin Exp Med. 2020;29(8):959-966. doi:10.17219/acem/123352

DOI

10.17219/acem/123352

\section{Copyright}

Copyright by Author(s)

This is an article distributed under the terms of the

Creative Commons Attribution 3.0 Unported (CC BY 3.0)

(https://creativecommons.org/licenses/by/3.0/)

\begin{abstract}
Background. Ischemic encephalopathy is a common clinical disease. The main treatment goal is to achieve vascular recanalization. However, after vascular recanalization, the reperfusion of fresh blood can change local cell metabolism, thus adversely affecting cell structure and function, which can result in reperfusion injury.

Objectives. To explore the effect of matrine intervention of different concentrations on JAK2/STAT3 signaling pathway and brain protection in rats with cerebral ischemia-reperfusion.

Material and methods. Healthy male Sprague Dawley rats were divided into a blank control group (20 rats), a model group ( 80 rats) and a sham group (20 rats). In the model group, the middle cerebral artery was occluded with suture method to establish cerebral ischemia-reperfusion model rats, which were subdivided into cerebral ischemia-reperfusion group, and 5, 10 and $20 \mathrm{mg} / \mathrm{kg}$ matrine groups, with 20 rats in each group. Indicators including neurological function score, brain infarct size, brain water content, lactic dehydrogenase activity, protein expressions of p-JAK2 and p-STAT3, as well as superoxide dismutase activity and malondialdehyde content were evaluated.
\end{abstract}

Results. Compared with cerebral ischemia-reperfusion group, all the indicators were significantly improved in the 3 matrine treatment groups in a dose-dependent manner, and protein expressions of p-JAK2 and p-STAT3 in the brain tissue and brain cell apoptosis rate were decreased with the increase of matrine concentration (all $p<0.05)$.

Conclusions. Matrine can significantly ameliorate the neurological function and brain edema of rats with cerebral ischemia-reperfusion, and improve superoxide dismutase, malondialdehyde and lactic dehydrogenase levels in the brain tissue and brain cell apoptosis rate. The mechanism of matrine may be related to the inhibition of abnormal JAK2/STAT3 signaling pathway activation.

Key words: ischemia-reperfusion injury, motor function, JAK2/STAT3 signaling pathway, neurological function, matrine cerebral 


\section{Introduction}

Reperfusion injury is common in ischemic encephalopathy. ${ }^{1,2}$ After the occurrence of cerebral ischemia-reperfusion, brain cells will gradually die in the form of apoptosis; the occurrence of cerebral ischemia-reperfusion also leads to neuron necrosis and neurological deficit.,

Matrine is a kind of monomeric compound extracted from Sophora flavescens, a legume plant. It not only has anti-tumor and anti-oxidation effect, but also protects the cardiocerebral vascular system from injuries to some extent. ${ }^{5,6}$ A previous study in rats has revealed that matrine can suppress myocardial injury induced by septic shock by inhibiting JAK2/STAT3 signaling pathway activation.? As for the effect of matrine on cerebral ischemia-reperfusion, some studies suggested that matrine could exert a protective effect on neurons of rats with cerebral ischemiareperfusion by activating cannabinoid receptor type $2 .{ }^{8}$

Janus kinase - signal transducer and activator transcription (JAK/STAT) signaling pathway is closely related to the occurrence of cerebral ischemia-reperfusion injury. ${ }^{9}$ A recent study has shown that the inhibition of JAK2/ STAT3 signaling pathway activation can inhibit neuron apoptosis, thereby alleviating cerebral ischemia-reperfusion injury. ${ }^{10}$ However, there is no report on whether matrine could protect brain damage through JAK2/STAT3 signaling pathway in cerebral ischemia-reperfusion rat models.

Therefore, to further explore the neuroprotective effect of matrine in cerebral ischemia-reperfusion and its potential regulatory mechanism, we investigated the effect of different concentrations of matrine on JAK2/STAT3 signaling pathway in cerebral ischemia-reperfusion rat models.

\section{Material and methods}

\section{Animals and material}

A total of 120 healthy male SD rats, aged 8 weeks and weighed $170.68 \pm 7.39 \mathrm{~g}$, were obtained from the Laboratory Animal Center of Hebei Medical University (certificate No. 712065). Rats were housed in a plastic case with bedding on the solid bottom at a constant temperature of $22^{\circ} \mathrm{C}$ and a relative humidity of $50 \sim 65 \%$ in a normal day and night circle of $12 / 12 \mathrm{~h}$. Rats were provided free access to food and water. The operation in the modeling process conformed to the standards of the Experimental Animal Ethics Committee of our hospital, by which this study was approved.

Matrine was purchased from the Ningxia Zijinhua Pharmaceutical Co., Ltd., Wuzhong, China (batch No. 90161019; purity $\geq 99 \%$ ). The $0.9 \%$ sodium chloride injection was purchased from the Hunan Kelun Pharmaceutical Co., Ltd., Chengdu, China (batch No. 2A16030602). TUNEL apoptosis detection kit was purchased from the Wuhan Boster
Biological Technology Co., Ltd., Wuhan, China (batch No. BAO621). Primary antibodies JAK2, p-JAK2, STAT3, p-STAT3 and $\beta$-actin were purchased from the Shanghai Anyan Trade Co., Ltd., Shanghai, China. Goat anti-rabbit secondary antibody was purchased from the Abcam (Shanghai, China) Trade Co., Ltd., China (1:2,000, batch No. ab6721). Paraffin embedding center and rotary microtome were purchased from the Leica Biosystems Inc., Wetzlar, Germany. Optical microscope and microscope imaging analysis system were purchased from the Olympus Optical Co., Ltd., Tokyo, Japan. Lactic dehydrogenase (LDH), superoxide dismutase (SOD) and malondialdehyde (MDA) detection kits were purchased from the Wuhan MSK Biotechnology Co., Ltd., Wuhan, China.

\section{Modeling}

Rats were divided into a model group (80 rats), a sham group (20 rats) and a blank control group (20 rats). Rats in the blank control group were fed routinely without intervention. Rats in the model group were used to establish the model of cerebral ischemia-reperfusion. The specific modeling process was as follows. Rats were firstly anesthetized with $3 \mathrm{~mL} / \mathrm{kg} 10 \%$ chloral hydrate. Then, the anesthetized rats were fixed on the operating table in the supine position. After routine skin preparation and disinfection, the skin was cut open lengthways through the middle of the neck, and the common carotid artery, external carotid artery and internal carotid artery were separated. Then, the common carotid artery and internal carotid artery were occluded using silk sutures. A small incision was cut on the wall of the external carotid artery at $3 \mathrm{~mm}$ from the arterial intersection. A nylon thread was inserted into the incision and pushed slowly towards the internal carotid artery until encountering resistance at a push-in depth of about $20 \mathrm{~mm}$. At this moment, the nylon thread reached into the anterior cerebral artery and blocked the blood supply to the middle cerebral artery. Then, the external carotid artery was tightened, and the skin was sutured. Two hours later, the nylon thread was pulled outwards to the external carotid artery to develop cerebral ischemia-reperfusion. After the rats were revived, they were sent back to the cage for continuous feeding. Rats that walked towards the contralateral side or circled to their tails after operation indicated successful modeling. In the sham group, the artery of the rat was separated only without subsequent artery ligation, nylon thread insertion, etc., and other procedures, such as skin suture, were the same as in the model group.

Rats in the model group were subdivided into cerebral ischemia-reperfusion group, $5 \mathrm{mg} / \mathrm{kg}$ matrine group, $10 \mathrm{mg} / \mathrm{kg}$ matrine group, and $20 \mathrm{mg} / \mathrm{kg}$ matrine group, with 20 rats in each group. In the 3 matrine groups, matrine solutions (concentrations of $5 \mathrm{mg} / \mathrm{kg}, 10 \mathrm{mg} / \mathrm{kg}$ and $20 \mathrm{mg} / \mathrm{kg}$ ) were intraperitoneally injected into the rats 
30 min before ischemia and $2 \mathrm{~h}$ after ischemia. ${ }^{11}$ Rats in the cerebral ischemia-reperfusion group, the sham group and the blank control group were intraperitoneally injected with the same amount of normal saline at same time points.

\section{Neurological function scoring}

Neurological function was scored by Longa method $24 \mathrm{~h}$ after operation. ${ }^{12}$ Detailed scoring rules were as follows: no neurological function deficit was scored as 0; mild neurological function deficit (contralateral fore limbs could not be fully outstretched) was scored as 1 ; moderate neurological function deficit (rats circled to the contralateral side) was scored as 2; severe neurological function deficit (rats toppled towards the contralateral side) was scored as 3 ; the symptom that rats could not walk and had clouding of consciousness was scored as 4 .

\section{Brain infarct size calculation}

After neurological function evaluation, 5 rats were randomly selected and euthanatized by cervical dislocation. The brain tissue was taken out and frozen in a refrigerator at $-20^{\circ} \mathrm{C}$ for $10 \mathrm{~min}$. The infarct area was cut into sections from the coronal plane of anterior and posterior optic chiasma, with a thickness of $2 \mathrm{~mm}$. Serial sections were incubated away from light in 1\% 2,3,5-triphenyl-tetrazolium chloride (TTC) solution at $37^{\circ} \mathrm{C}$ for $20 \mathrm{~min}$. The percentage of brain infarct size was calculated. Percentage of brain infarct size $(\%)=$ brain infarct size/total size of brain infarct section * $100 \%$.

\section{Detection of brain water content}

Five rats in each group were randomly selected and sacrificed. Wet weight of the brain was weighed after removal of the olfactory bulb, cerebellum and lower brain stem. Then the brain was baked at $108^{\circ} \mathrm{C}$ for $72 \mathrm{~h}$. Dry weight of the brain was weighed. Brain water content $(\%)=($ wet weight - dry weight)/wet weight $\times 100 \%$.

\section{Detection of SOD activity, MDA content and LDH activity in the brain tissue}

Five rats were randomly selected and sacrificed $24 \mathrm{~h}$ after model establishment. A part of the brain tissue was taken out and ground. The ground brain tissues were put into a test tube with the addition of $25 \%$ trypsin and incubated in a water bath at $37^{\circ} \mathrm{C}$. After digestion, the solution was blown with a pipette to be homogeneous and centrifuged at $1,000 \mathrm{r} / \mathrm{min}$ for $5 \mathrm{~min}$. The supernatant was collected and washed with phosphate-buffered saline (PBS) to prepare tissue suspension. LDH activity, SOD activity and MDA content in the brain tissue were measured with chemical colorimetry method, xanthine oxidase method and thiobarbituric acid method, respectively.

\section{Detection of brain cell apoptosis rate with TUNEL method}

Additional 5 rats were randomly selected. The brain infarct area was cut into sections to prepare specimens. Proteins of the brain tissue were digested at room temperature with $20 \mu \mathrm{g} / \mathrm{mL}$ protease $\mathrm{K}$ and rinsed 4 times with distilled water. Then, the section was incubated with TUNEL reaction mixture for $50 \mathrm{~min}$ and incubated with anti-fluorescein-dUTP. 3'-diaminobenzidine (DAB) coloration was performed. Five different visual fields on the infarct area were randomly selected under a light microscope to observe and count apoptotic cells. The brownish yellow showed positive apoptotic cells. Apoptosis rate (\%) = number of apoptotic cells/total number of cells $\times 100 \%$.

Detection of JAK2, p-JAK2, STAT3, and p-STAT3 protein expressions measured with western blot

Partial tissue suspension prepared during the detection of SOD activity, MDA content and LDH activity in the brain tissue was lysed with RIPA lysis buffer and mixed on the ice. The mixture was centrifuged at $1,300 \mathrm{r} / \mathrm{min}$ for $10 \mathrm{~min}$. Then, the proteins were separated using 10\% SDS-PAGE and transferred to polyvinylidene difluoride (PVDF) membranes. The membrane was sealed with $5 \%$ skim milk overnight at $4{ }^{\circ} \mathrm{C}$. Then the membrane was incubated with primary antibodies JAK2 (1:1,000), p-JAK2 (1:1,000), STAT3 (1:1,000), p-STAT3 (1:1,000), and $\beta$-actin $(1: 1,000)$ overnight at $4{ }^{\circ} \mathrm{C}$ and horseradish peroxidase (HRP)-labeled goat anti-rabbit immunoglobulin ( $2^{\text {nd }}$ antibody, $1: 1,200$ ) at room temperature for $1 \mathrm{~h}$. The membrane was rinsed with PBS and color development was carried out using ECL developer. The results were expressed as gray value of the target band/gray value of the internal reference.

\section{Statistical analysis}

SPSS v. 19.0 software (IBM Corp., Armonk, USA) was adopted to analyze the collected data. The measurement data was expressed as mean \pm standard deviation (SD). Comparison among groups was performed with oneway analysis of variance (ANOVA) followed by post hoc pairwise comparison using Least Significant Difference (LSD)/t test. A p $<0.05$ indicated that the difference was statistically significant.

\section{Results}

\section{Neurological function scores}

Neurological function scores at $24 \mathrm{~h}$ after operation in the blank control group, the sham group, the cerebral ischemia-reperfusion group, the $5 \mathrm{mg} / \mathrm{kg}$ matrine group, 


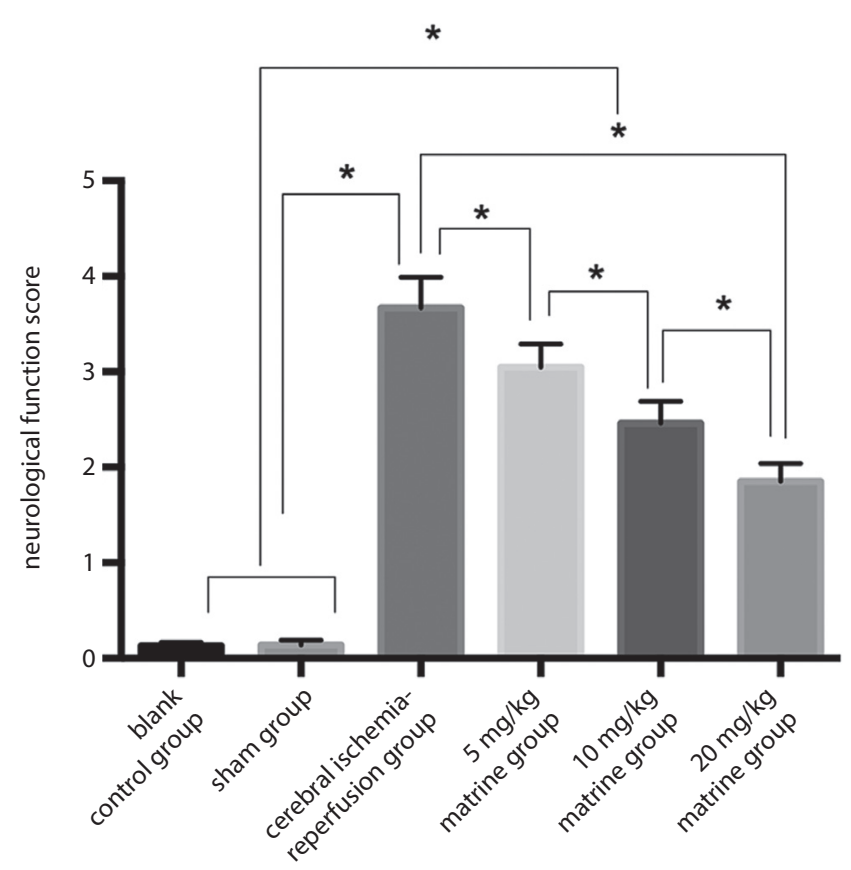

Fig. 1. Neurological function score ${ }^{*} p<0.05$. the $10 \mathrm{mg} / \mathrm{kg}$ matrine group, and the $20 \mathrm{mg} / \mathrm{kg}$ matrine group were $0.13 \pm 0.04,0.14 \pm 0.05,3.67 \pm 0.32,3.05 \pm 0.24$, $2.46 \pm 0.23$, and $1.85 \pm 0.19$ scores, respectively; there were no significant differences in neurological function scores between the blank control group and the sham group ( $p>0.05$ ). Neurological function scores in cerebral ischemia-reperfusion group were significantly higher than those in the sham group, the blank control group, the $5 \mathrm{mg} / \mathrm{kg}$ matrine group, the $10 \mathrm{mg} / \mathrm{kg}$ matrine group, and the $20 \mathrm{mg} / \mathrm{kg}$ matrine group. Neurological function scores were the highest in the $5 \mathrm{mg} / \mathrm{kg}$ matrine group, followed by the $10 \mathrm{mg} / \mathrm{kg}$ matrine group and the $20 \mathrm{mg} / \mathrm{kg}$ matrine group (all $\mathrm{p}<0.05$, Fig. 1 ).

\section{Brain infarct size}

Brain infarct size at $24 \mathrm{~h}$ after operation in the blank control group, the sham group, the cerebral ischemia-reperfusion group, the $5 \mathrm{mg} / \mathrm{kg}$ matrine group, the $10 \mathrm{mg} / \mathrm{kg}$ matrine group and the $20 \mathrm{mg} / \mathrm{kg}$ matrine group was $0 \%$, $0 \%,(31.54 \pm 1.45) \%,(25.32 \pm 1.21) \%,(20.06 \pm 1.02) \%$, and $(15.33 \pm 0.97) \%$, respectively. Brain infarct size in cere-

A

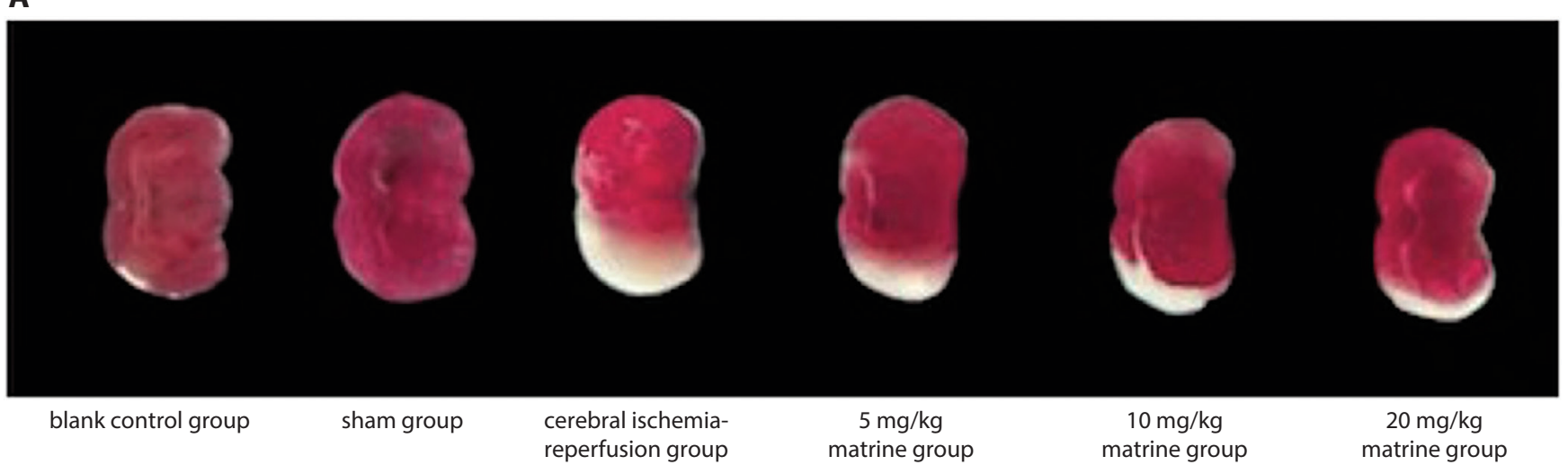

B

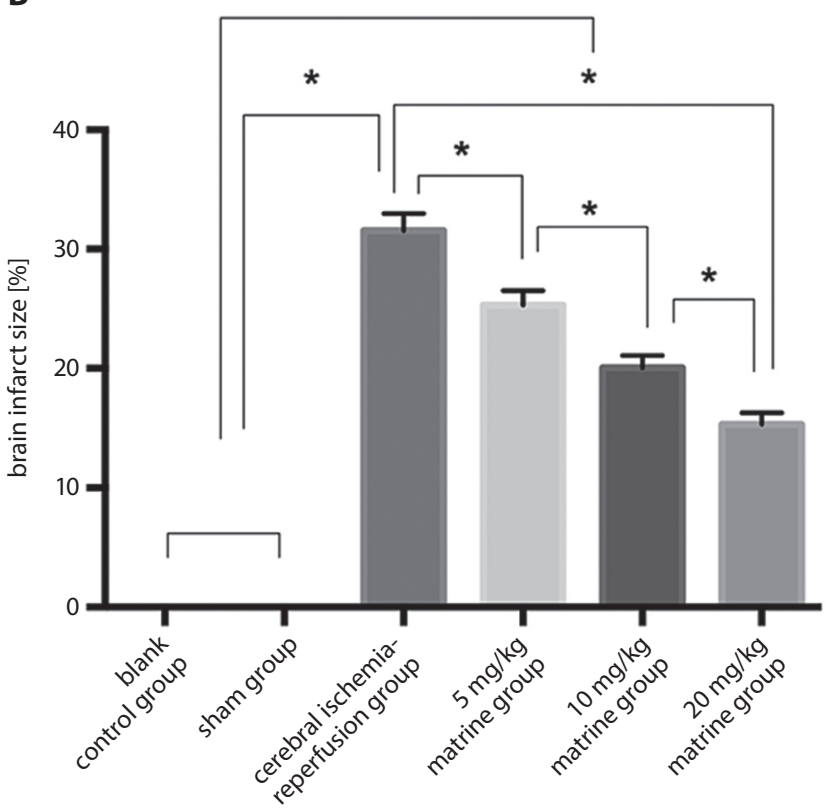

Fig. 2. Brain infarct size

A - picture of brain infarct; $B$ - brain infarct size comparison; ${ }^{*} p<0.05$.

bral ischemia-reperfusion group was significantly larger than that in the sham group, the blank control group, the $5 \mathrm{mg} / \mathrm{kg}$ matrine group, the $10 \mathrm{mg} / \mathrm{kg}$ matrine group, and the $20 \mathrm{mg} / \mathrm{kg}$ matrine group. Rats in the $20 \mathrm{mg} / \mathrm{kg}$ matrine group had the smallest brain infarct size, followed by the $10 \mathrm{mg} / \mathrm{kg}$ matrine group and the $5 \mathrm{mg} / \mathrm{kg}$ matrine group (all $\mathrm{p}<0.05$, Fig. 2).

\section{Brain water content}

Brain water content at $24 \mathrm{~h}$ after operation in the blank control group, the sham group, cerebral ischemia-reperfusion group, the $5 \mathrm{mg} / \mathrm{kg}$ matrine group, the $10 \mathrm{mg} / \mathrm{kg}$ matrine group, and the $20 \mathrm{mg} / \mathrm{kg}$ matrine 


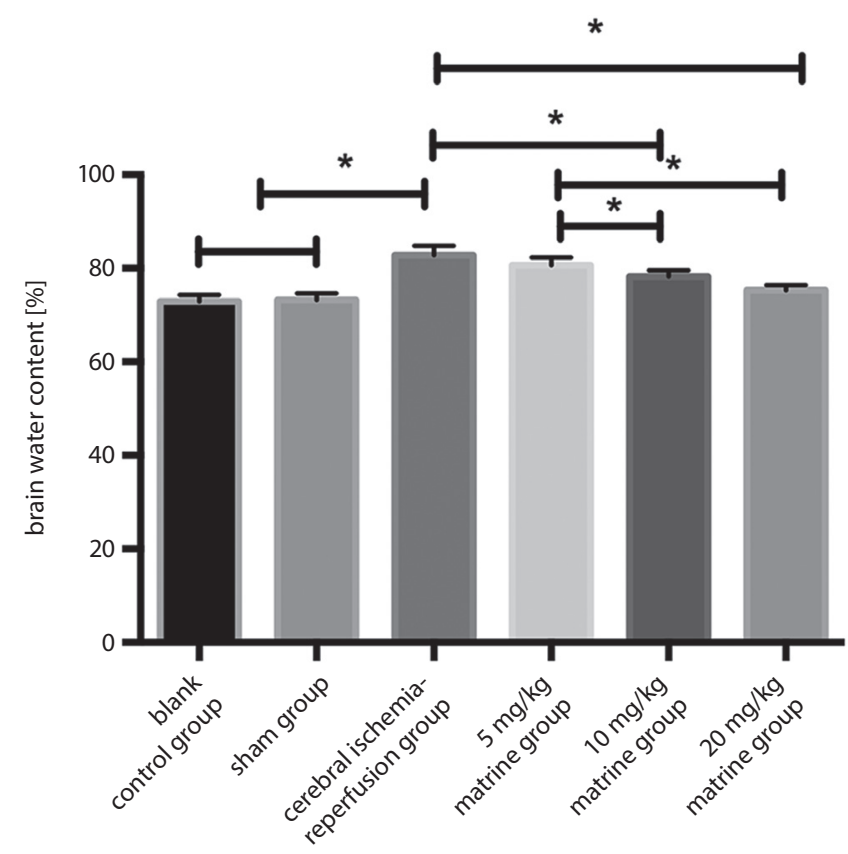

Fig. 3. Brain water content. Brain water content in cerebral ischemiareperfusion group was significantly higher than that in sham group, blank control group, $10 \mathrm{mg} / \mathrm{kg}$ matrine group, and $20 \mathrm{mg} / \mathrm{kg}$ matrine group. Brain water content in $5 \mathrm{mg} / \mathrm{kg}$ matrine group was significantly higher than that in $10 \mathrm{mg} / \mathrm{kg}$ matrine group and $20 \mathrm{mg} / \mathrm{kg}$ matrine group group was $(72.87 \pm 1.39) \%,(73.21 \pm 1.42) \%$, $(82.76 \pm 2.03) \%$, $(80.64 \pm 1.66) \%$, $(78.21 \pm 1.34) \%$, and $(75.26 \pm 1.15) \%$, respectively; brain water content at $24 \mathrm{~h}$ after operation in the cerebral ischemia-reperfusion group was significantly higher than that in the sham group and the blank control group (both $\mathrm{p}<0.05$ ). Brain water content of rats treated with matrine was reduced in dose-dependent manner; brain water content in the $10 \mathrm{mg} / \mathrm{kg}$ matrine group and the $20 \mathrm{mg} / \mathrm{kg}$ matrine group was significantly lower than that in the cerebral ischemia-reperfusion group (both $\mathrm{p}<0.05$, Fig. 3).

\section{SOD, MDA and LDH levels in the brain tissue}

Rats in the sham group had significantly lower MDA and LDH levels and higher SOD level than cerebral ischemia-reperfusion group (all $\mathrm{p}<0.05)$. Compared with cerebral ischemia-reperfusion group, SOD, MDA and LDH levels in the $5 \mathrm{mg} / \mathrm{kg}$ matrine group, the $10 \mathrm{mg} / \mathrm{kg}$ matrine group and the $20 \mathrm{mg} / \mathrm{kg}$ matrine group were significantly improved, and the improvement was more significant with the increase of matrine concentration (all p $<0.05$, Table 1).

A

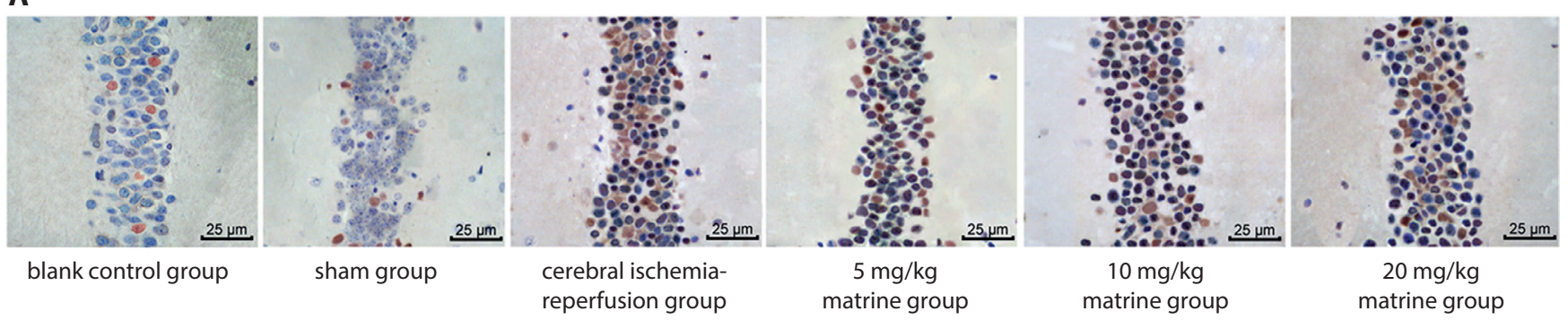

B

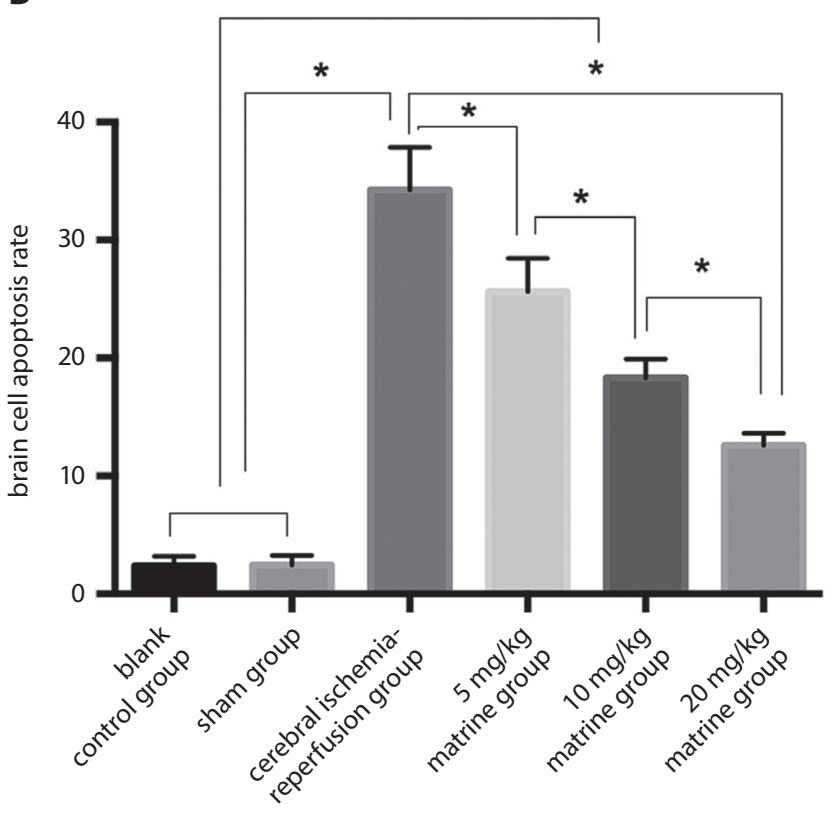

Fig. 4. Brain cell apoptosis rate

A - brain cell apoptosis diagram using TUNEL; B - histogram of brain cell apoptosis rate; ${ }^{*} p<0.05$.

\section{Brain cell apoptosis rate}

Brain cell apoptosis rate at $24 \mathrm{~h}$ after operation in the blank control group, the sham group, the cerebral ischemia-reperfusion group, the $5 \mathrm{mg} / \mathrm{kg}$ matrine group, the $10 \mathrm{mg} / \mathrm{kg}$ matrine group, and the $20 \mathrm{mg} / \mathrm{kg}$ matrine group was $(2.39 \pm 0.78) \%$, $(2.45 \pm 0.81) \%$, (34.26 \pm 3.59$) \%$, (25.61 \pm 2.85$) \%,(18.33 \pm 1.59) \%$, and $(12.57 \pm 1.04) \%$, respectively. Brain cell apoptosis rate in cerebral ischemia-reperfusion group was significantly higher than in the sham group, the blank control group, the $5 \mathrm{mg} / \mathrm{kg}$ matrine group, the $10 \mathrm{mg} / \mathrm{kg}$ matrine group, and the $20 \mathrm{mg} / \mathrm{kg}$ matrine group. Rats in the $20 \mathrm{mg} / \mathrm{kg}$ matrine group had the lowest brain cell apoptosis rate, followed by the $10 \mathrm{mg} / \mathrm{kg}$ matrine group and the $5 \mathrm{mg} / \mathrm{kg}$ matrine group (all p $<0.05$, Fig. 4). 
Table 1. SOD, MDA and LDH levels in the brain tissue

\begin{tabular}{|c|c|c|c|}
\hline Variable & $\mathrm{SOD}[\mathrm{U} / \mathrm{mg}]$ & MDA [nmol/mg] & LDH [U/mg] \\
\hline Blank control group $(n=5)$ & $91.65 \pm 18.97$ & $0.82 \pm 0.11$ & $2210.957 \pm 273.65$ \\
\hline Sham group $(\mathrm{n}=5)$ & $91.76 \pm 19.33$ & $0.84 \pm 0.12$ & $2215.97 \pm 276.81$ \\
\hline Cerebral ischemia-reperfusion group $(n=5)$ & $41.27 \pm 14.65^{* \#}$ & $1.79 \pm 0.35^{* \#}$ & $7268.25 \pm 341.63^{* \#}$ \\
\hline $5 \mathrm{mg} / \mathrm{kg}$ matrine group $(\mathrm{n}=5)$ & $61.32 \pm 12.48^{* \# \&}$ & $1.48 \pm 0.29^{* \# \&}$ & $6738.46 \pm 295.68^{* \# \&}$ \\
\hline $10 \mathrm{mg} / \mathrm{kg}$ matrine group $(n=5)$ & $69.79 \pm 13.39^{* \# \& @ ~}$ & $1.26 \pm 0.23 * \# \& @$ & $4395.77 \pm 285.35^{* \# \& @}$ \\
\hline 20 mg/kg matrine group $(n=5)$ & $78.86 \pm 12.28^{* \# \& @ \$}$ & $1.09 \pm 0.13^{* \# \& @ \$}$ & $3859.45 \pm 288.86^{* \# \& @ \$}$ \\
\hline $\mathrm{F}$ & 7.89 & 14.17 & 271.3 \\
\hline p-value & $<0.001$ & $<0.001$ & $<0.001$ \\
\hline
\end{tabular}

SOD - superoxide dismutase; MDA - malondialdehyde; LDH - lactic dehydrogenase; ${ }^{*} \mathrm{p}<0.05$ - compared with blank control group; ${ }^{*} \mathrm{p}<0.05$ - compared with sham group; \& $p<0.05$ - compared with cerebral ischemia-reperfusion group; ${ }^{\circledR} p<0.05$ - compared with 5 mg/kg matrine group; $\$ p<0.05$ - compared with $10 \mathrm{mg} / \mathrm{kg}$ matrine group.

Table 2. JAK2, STAT3, p-JAK2, and p-STAT3 protein expressions in the brain tissue

\begin{tabular}{|c|c|c|c|c|}
\hline Variable & JAK2 & STAT3 & p-JAK2 & p-STAT3 \\
\hline Blank control group $(n=5)$ & $1.15 \pm 0.13$ & $1.13 \pm 0.12$ & $0.20 \pm 0.08$ & $0.12 \pm 0.03$ \\
\hline Sham group $(n=5)$ & $1.14 \pm 0.12$ & $1.12 \pm 0.10$ & $0.21 \pm 0.09$ & $0.13 \pm 0.02$ \\
\hline $\begin{array}{l}\text { Cerebral ischemia-reperfusion } \\
\text { group }(n=5)\end{array}$ & $0.38 \pm 0.07^{* \#}$ & $0.29 \pm 0.04^{* \#}$ & $0.41 \pm 0.06^{* \#}$ & $0.60 \pm 0.09^{* \#}$ \\
\hline $5 \mathrm{mg} / \mathrm{kg}$ matrine group $(\mathrm{n}=5)$ & $0.45 \pm 0.05^{* \# \& \&}$ & $0.41 \pm 0.06^{* \# \&}$ & $0.35 \pm 0.08^{* \# \&}$ & $0.47 \pm 0.06^{* \# \&}$ \\
\hline $10 \mathrm{mg} / \mathrm{kg}$ matrine group $(\mathrm{n}=5)$ & $0.58 \pm 0.06^{* \# \& \&}$ & $0.57 \pm 0.06^{* \# \& @}$ & $0.29 \pm 0.07^{* \# \& @ ~}$ & $0.34 \pm 0.05^{* \# \& @ ~}$ \\
\hline 20 mg/kg matrine group $(n=5)$ & $0.71 \pm 0.07^{* \# \& @ ~}$ & $0.69 \pm 0.07^{* \# \& @ \$}$ & $0.25 \pm 0.03^{* \# \& @ \$ ~}$ & $0.22 \pm 0.04^{* \# \& @ \$}$ \\
\hline $\mathrm{F}$ & 72.221 & 99.293 & 6.734 & 65.662 \\
\hline p-value & $<0.001$ & $<0.001$ & $<0.001$ & $<0.001$ \\
\hline
\end{tabular}

${ }^{*} \mathrm{p}<0.05$ - compared with blank control group; ${ }^{\mathrm{p}}<0.05$ - compared with sham group; ${ }^{\mathrm{p}} \mathrm{p}<0.05$ - compared with cerebral ischemia-reperfusion group; ${ }^{\circledR} p<0.05$ - compared with $5 \mathrm{mg} / \mathrm{kg}$ matrine group; $\$ p<0.05$ - compared with $10 \mathrm{mg} / \mathrm{kg}$ matrine group.

JAK2

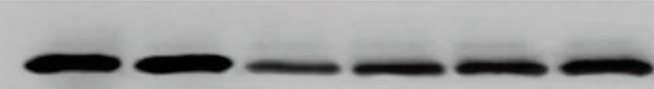

p-JAK2

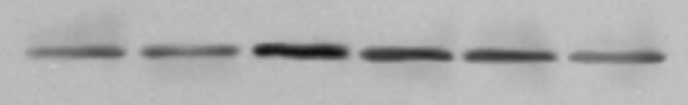

STAT3

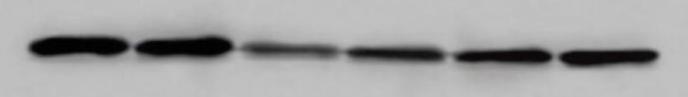

p-STAT3

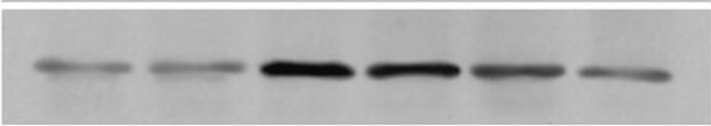

$\beta$-actin
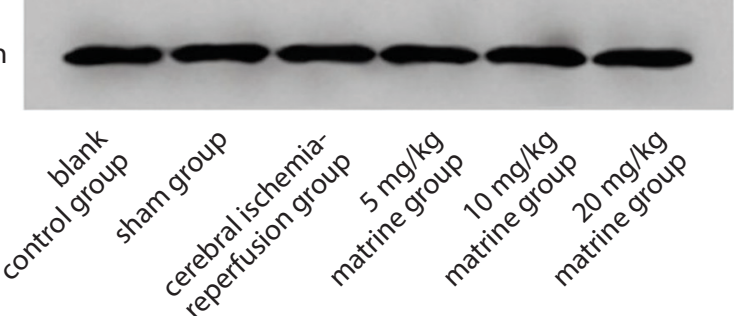

Fig. 5. Protein bands in western blot

\section{Protein expressions of JAK2, p-JAK2, STAT3, and p-STAT3 in the brain tissue}

Rats in the cerebral ischemia-reperfusion group had significantly greater p-JAK2 and p-STAT3 protein expressions and lower JAK2 and STAT3 protein expressions than the blank control group and the sham group (all $\mathrm{p}<0.05$ ). In the $5 \mathrm{mg} / \mathrm{kg}$ matrine group, the $10 \mathrm{mg} / \mathrm{kg}$ matrine group and the $20 \mathrm{mg} / \mathrm{kg}$ matrine group, p-JAK2 and p-STAT3 protein expressions were significantly decreased, and JAK2 and STAT3 protein expressions were significantly elevated, compared with the cerebral ischemia-reperfusion group; p-JAK2 and p-STAT3 protein expressions dropped with the increase of matrine concentration, and JAK2 and STAT3 protein expressions ascended with the increase of matrine concentration (all $\mathrm{p}<0.05$, Table 2, Fig. 5).

\section{Discussion}

In this study, cerebral ischemia-reperfusion rat models were established using suture method and matrine intervention was administrated to rats at different concentrations to explore the curative effect of matrine on cerebral 
ischemia-reperfusion and its possible mechanism. The results of neurological function evaluation indicated that rats with cerebral ischemia-reperfusion suffered from significant neurological function deficit, while matrine could relieve cerebral ischemia-reperfusion injuries in rats.

Neurons are poorly tolerant to hypoxia ischemia. Therefore, cerebral ischemia-reperfusion causes neuron necrosis and further leads to neurological function deficit. ${ }^{13,14}$ The results in this study found that matrine could improve neurological function deficit of rats with cerebral ischemiareperfusion to some extent.

In addition, brain infarct size and brain water content of rats treated with matrine were lowered with the increase of matrine concentration, suggesting that cerebral ischemia-reperfusion in rats not only caused cerebral infarction, but also resulted in brain edema. Results of some studies indicated that matrine could decrease the degree of brain edema caused by middle cerebral artery occlusion in rats and effectively lessen brain infarct size of rats in cerebral infarction rat models, ${ }^{15,16}$ which were consistent with the results of our study, indicating that matrine could reduce the degree of cerebral edema and cerebral infarction in rats with cerebral ischemia-reperfusion.

In addition, we found that matrine can increase the activity of SOD, reduce the content of MDA, improve energy metabolism, and inhibit the increase of LDH content and the apoptosis of nerve cells caused by brain injury. When cerebral ischemia-reperfusion occurs, uncoupling of oxidative phosphorylation takes place in the mitochondria, and a great number of free radicals are generated. ${ }^{17}$ The SOD can catalyze and scavenge the disproportionated reaction of free radicals, while the change of MDA content can indirectly reflect the change of oxygen radicals; cerebral ischemia leads to the release of a large number of intracellular LDHs, which further induces brain cell damage. ${ }^{18,19}$ After the occurrence of cerebral ischemia-reperfusion, the death procedure of brain cells is activated, mainly manifesting in neuron apoptosis..$^{20,21}$ These findings were in line with the results of our study, indicating that matrine can reduce the neuronal apoptosis of rats after cerebral ischemia and reperfusion to protect the rat brain tissue.

When cerebral ischemia-reperfusion occurs, the expressions of phosphorylated JAKs and STATs in the brain tissue are significantly increased. ${ }^{22,23}$ The results in our study showed that the abnormal activation of JAK2/STAT3 signaling pathway and the phosphorylation of JAK2 and STAT3 proteins in model rats might play an important role in cerebral ischemia-reperfusion injuries. Besides, after matrine intervention, rats had decreased p-JAK2 and p-STAT3 protein expressions and increased JAK2 and STAT3 protein expressions in the brain tissue, and the decrease of p-JAK2 and p-STAT3 protein expressions was more significant with the increase of matrine concentration. A study reported that inhibiting the activation of JAK2/STAT3 signaling pathway could restrain the inflammatory response induced by cerebral ischemia-reperfusion injuries and thereby lessen neuron apoptosis. ${ }^{24}$ Therefore, we hypothesize that the neuroprotective effect of matrine on cerebral ischemia-reperfusion model rats might be exerted by the activation of JAK2/STAT3 signaling pathway and the inhibition of JAK2 and STAT3 protein phosphorylation. However, we have not explored other potential mechanisms in this study. Thus, our results remain to be further verified in the future.

\section{Conclusions}

Matrine can significantly improve neurological function and brain edema of rats with cerebral ischemia-reperfusion and ameliorate SOD, MDA and LDH levels as well as apoptosis rate in the brain tissue by inhibiting abnormal activation of JAK2/STAT3 signaling pathway.

\section{ORCID iDs}

Jixing Chen (D) https://orcid.org/0000-0001-8073-9638 Cuiqin Huang (I) https://orcid.org/0000-0002-0676-2351 Lichao Ye (D) https://orcid.org/0000-0001-5748-1077 Boxin Yao (D) https://orcid.org/0000-0002-3634-5364 Meili Yang (D) https://orcid.org/0000-0002-9912-2774 Qiankun Cai (i) https://orcid.org/0000-0001-8725-1934

\section{References}

1. Li Y, Liu S. The effect of dexmedetomidine on oxidative stress response following cerebral ischemia-reperfusion in rats and the expression of intracellular adhesion molecule-1 (ICAM-1) and S100B. Med Sci Monit. 2017;23:867-873.

2. Che N, Ma Y, Xin Y. Protective role of fucoidan in cerebral ischemiareperfusion injury through inhibition of MAPK signaling pathway. Biomol Ther (Seoul). 2017;25(3):272-278.

3. Lu H, Wang B. SIRT1 exerts neuroprotective effects by attenuating cerebral ischemia/reperfusion-induced injury via targeting p53/ microRNA-22. Int J Mol Med. 2017;39(1):208-216.

4. Duan S, Wang T, Zhang J, et al. Huatuo Zaizao pill promotes functional recovery and neurogenesis after cerebral ischemia-reperfusion in rats. BMC Complement Altern Med. 2017;17:19.

5. Chen L, Wang F, Han Z. Effects of matrine on inflammatory cytokines for rats with cerebral ischemia reperfusion injury. Journal of Emergency in Traditional Chinese Medicine. 2010;19:2098-2099.

6. Meng FR, Wang YJ, Kong YM, Wang D, Chen C. Matrine alleviated incomplete cerebral ischemia-reperfusion injury in mice. Journal of Liaoning University. 2011;4:350-352.

7. Zhang $M$, Wang $X$, Wang $X$, et al. Oxymatrine protects against myocardial injury via inhibition of JAK2/STAT3 signaling in rat septic shock. Mol Med Rep. 2013;7(4):1293-1299.

8 Tang M, Dong Z, Cai JH, et al. Pharmacology DO. Neuroprotective effects of matrine by activating cannabinoid 2 receptor on focal cerebral ischemia-reperfusion injury in rats. Chinese Journal of New Drugs \& Clinical Remedies. 2014;33:311-316.

9. Hu GQ, Du X, Li YJ, Gao XQ, Chen BQ, Yu L. Inhibition of cerebral ischemia/reperfusion injury-induced apoptosis: Nicotiflorin and JAK2/ STAT3 pathway. Neural Regen Res. 2017;12(1):96-102.

10. Chang C, Zhao Y, Song G, She K. Resveratrol protects hippocampal neurons against cerebral ischemia-reperfusion injury via modulating JAK/ERK/STAT signaling pathway in rats. J Neuroimmunol. 2018;315: 9-14.

11. Li P, Lei J, Hu G, Chen X, Liu Z, Yang J. Matrine mediates inflammatory response via gut microbiota in TNBS-induced murine colitis. Front Physiol. 2019;10:28.

12. Liu YZ, Wang C, Wang $Q$, et al. Role of fractalkine/CX3CR1 signaling pathway in the recovery of neurological function after early ischemic stroke in a rat model. Life Sci. 2017;184:87-94. 
13. Singh V, Krishan P, Shri R. Improvement of memory and neurological deficit with Ocimum basilicum I. extract after ischemia reperfusion induced cerebral injury in mice. Metab Brain Dis. 2018:33(4):1111-1120.

14. Min L, Xiangjian Z, Lili C, et al. The neuroprotection of oxymatrine in cerebral ischemia/reperfusion is related to nuclear factor erythroid 2-related factor 2 (nrf2)-mediated antioxidant response: Role of nrf2 and hemeoxygenase-1 expression. Biol Pharm Bull. 2011;34(5):595-601.

15. Hu ZL, Tan YX, Zhang JP, Qian DH. Effects of inhibitor of protein kinase C on brain edema formation evoked by experimental cerebral ischemia in gerbils and rats. Acta Pharmaceutica Sinica. 1996;31:886.

16. Liu Z, He D, Zhang X, et al. Neuroprotective effect of early and shorttime applying sophoridine in PMCAO rat brain: Down-regulated TRAF6 and up-regulated $p$-ERK1/2 expression, ameliorated brain infaction and edema. Brain Res Bull. 2012;88(4):379-384.

17. Wang SY, Xiao-Jiang W, Jin WZ, Tong CL, Yao LI. Effect of ginkgo biloba extract on SOD activity of and MDA level after cerebral ischemia reperfusion in rat [in Chinese]. Heilongjiang Medicine and Pharmacy. 2004;27(6):29.

18. Wang $X Y$, Zhang $Y Y$, Wan HT, et al. Protective effect of Shenxiong injection on cerebral ischemia/reperfusion injury of rats. China J Chin Mater Med. 2014;39:503-506.
19. Jiang CP, Liu F, Yi LI, et al. Effect of Shenfu injection on MDA, SOD, TXB_2 and 6-keto-PGF1a after cerebral ischemia/reperfusion injury in rats. J China Med Univ. 2012;41:124-127.

20. Gao XJ, Xie GN, Liu L, Fu ZJ, Zhang ZW, Teng LZ. Sesamol attenuates oxidative stress, apoptosis and inflammation in focal cerebral ischemia/reperfusion injury. Exp Ther Med. 2017;14(1):841-847.

21. Zhao P, Zhou RU, Zhu XY, et al. Matrine attenuates focal cerebral ischemic injury by improving antioxidant activity and inhibiting apoptosis in mice. Int J Mol Med. 2015;36(3):633-644.

22. Zhu H, Zou L, Tian J, Du G, Gao Y. SMND-309, a novel derivative of salvianolic acid $B$, protects rat brains ischemia and reperfusion injury by targeting the JAK2/STAT3 pathway. Eur J Pharmacol. 2013;714 $(1-3): 23-31$.

23. Xie HF, Ru-Xiang XU, Wei JP, Jiang XD. P-JAK2 and p-STAT3 protein expression and cell apoptosis following focal cerebral ischemiareperfusion injury in rats [in Chinese]. Nan Fang Yi Ke Da Xue Xue Bao. 2007;27(2):208-211,218.

24. Li L, Li H, Li M. Curcumin protects against cerebral ischemia-reperfusion injury by activating JAK2/STAT3 signaling pathway in rats. Int J Clin Exp Med. 2015;8(9):14985. 